\title{
BMJ Open Addressing rural and Indigenous health inequities in Canada through socially accountable health partnerships
}

\author{
Ray Markham (D) , ${ }^{1,2}$ Megan Hunt, ${ }^{3}$ Robert Woollard, ${ }^{1}$ Nelly Oelke, ${ }^{4}$ \\ David Snadden (1) , ${ }^{1,5}$ Roger Strasser, ${ }^{6}$ Georgia Betkus (1) , ${ }^{2,7}$ Scott Graham ${ }^{3}$
}

To cite: Markham R, Hunt M, Woollard R, et al. Addressing rural and Indigenous health inequities in Canada through socially accountable health partnerships. BMJ Open 2021;11:e048053. doi:10.1136/ bmjopen-2020-048053

- Prepublication history for this paper is available online. To view these files, please visit the journal online (http://dx.doi. org/10.1136/bmjopen-2020048053).

Received 16 December 2020 Accepted 02 October 2021

Check for updates

(c) Author(s) (or their employer(s)) 2021. Re-use permitted under CC BY-NC. No commercial re-use. See rights and permissions. Published by BMJ.

For numbered affiliations see end of article.

Correspondence to

Dr David Snadden;

david.snadden@ubc.ca

\section{ABSTRACT}

Background There are few examples of the practical application of the concepts of social accountability, as defined by the World Bank and WHO, to health system change. This paper describes a robust approach led by First Nations Health Authority and the Rural Coordination Centre of British Columbia. This was achieved using partnerships in British Columbia, Canada, where the health system features inequities in service and outcomes for rural and Indigenous populations. Social accountability is achieved when all stakeholders come together simultaneously as partners and agree on a path forward. This approach has enabled socially accountable healthcare, effecting change in the healthcare system by addressing the needs of the population.

Innovation Our innovative approach uses social accountability engagement to counteract persistent health inequities. This involves an adaptation of the Boelen Health Partnership model (policymakers, health administrators, health professionals, academics and community members) extended by addition of linked sectors (eg, industry and not-for-profits) to the 'Partnership Pentagram Plus'. We used appreciative inquiry and deliberative dialogue focused on the rural scale and integrating Indigenous ways of knowing along with western scientific traditions ('twoeyed seeing'). Using this approach, partners are brought together to identify common interests and direction as a learning community. Equitable engagement and provision of space as 'peers' and 'partners' were key to this process. Groups with varying perspectives came together to create solutions, building on existing strengths and new collaborative approaches to address specific issues in the community and health services delivery. A resulting provincial table reflecting the Pentagram Plus model has fostered policies and practices over the last 3 years that have resulted in meaningful collaborations for health service change.

Conclusion This paper presents the application of the 'Partnership Pentagram Plus' approach and uses appreciative inquiry and deliberative dialogue to bring about practical and positive change to rural and Indigenous communities.

\section{BACKGROUND}

There are persistent health and wellness inequities across multiple domains including rural, remote and Indigenous communities in Canada. ${ }^{1}$ One unique factor in British Columbia (BC) is the establishment of the First Nations Health Authority (FNHA) taking over the remit of First Nations Health from the Federal Government. The negative variance in population health between rural and urban populations is present throughout our world. ${ }^{2}$ These disparities are more prevalent in remote, resource-based and isolated First Nations communities as seen in BC, Canada. ${ }^{3}$ Their genesis is multifactorial, generally not from malice but from forces like economies of scale, system bias (eg, negative assumptions about rural $^{4}$ ), structural racism ${ }^{5}$ and historical and current day colonial systems of possession and control of Indigenous lands and services ${ }^{6-8}$ as well as critical mass perceptions to maintain service-all of which have created persistent inequities for decades. These forces can be seen as a gravitational pull to urban centres in health systems, including deliberate centralisation of services. We have demonstrated that it is possible to embed counter forces in community relationships and healthcare systems that mitigate this pull, moving towards a more socially accountable equitable, and just health system.

Boelen and colleagues ${ }^{9}$ developed a framework for social accountability in health professions education using an approach that identifies and engages equitably five distinct health partners (policymakers, health administrators, health professionals, academics and community members). These partners were described visually as a Partnership Pentagram $^{10}$ (figure 1). We (Rural Coordination Centre of British Columbia (RCCbc)) modified the Pentagram partners framework, adapted and applied it to rural health system change using the World Bank definition of social accountability: 'an approach toward building accountability that relies on civic engagement, in which citizens participate directly or indirectly in demanding 
Relationship Building

Partnership Pentagram

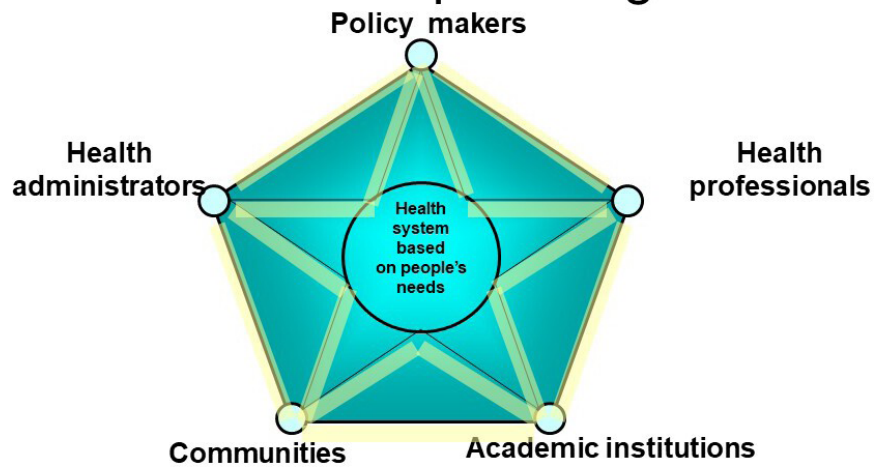

Figure 1 Partnership Pentagram. ${ }^{22}$

accountability from service providers and public officials'. ${ }^{11}$ A sixth partner of Linked Sectors, industry and not-for-profit organisations, was added and the framework is referred to as the Partnership Pentagram Plus (PPP) (figure 2). This is an expansion of the initial PPP supporting socially accountable health professions education $^{12}$ to a system wide process. We have applied this framework using an appreciative inquiry approach. ${ }^{13} 14$ This has been used as the foundation for creating a learning health system ${ }^{15}$ to improve health and wellness for rural and Indigenous people in BC.

\section{INNOVATION}

In the following sections, we have distilled some concepts and their application that may be transferable to other contexts. This has been shaped in partnership with First Nations on whose territories the province of BC and Canada have asserted contested jurisdiction and land ownership. The work of health system transformation using partnership-based approaches is one of the practical ways First Nations are reclaiming their health and wellness and helping shape this journey for all of Canada.

\section{Connecting as human beings}

Following the lead of our Indigenous partners, the importance of healthy relationships and recognising the intrinsic value of connecting as human beings (connection before action) is emphasised. Pragmatically, this results in us recognising that connecting is a part of any 'work' and needs to be valued as such. We start most of our small group work by checking in, recognising we are Human Beings not just Human Doings. Each person introduces themselves, shares something about who they are as a human being as well as what they do (their work 'hats'). In larger events, this can also be supported, by recognising First Nations Culture (eg, Elder openings, storytelling, traditional healers, cultural activities), grounding in community, environment and the people we serve.

\section{Partnership pentagram (versus pentagon)}

A pentagon has sides, and a pentagram has points connecting around the core. The purpose of the visual partnership pentagram diagram (figure 1) is to provide a succinct way of using and talking about the complexity of the partnership engagement framework and of ensuring all partner perspectives are simultaneously included. In BC rural health system contexts it became apparent that the five-partner approach was missing key perspectives. The framework was expanded to include linked sectors (notfor-profit organisations and industry), leading to the PPP.

We ask people to bring their perspective (versus being representatives) to this partner table to identify synergies for connecting and moving forward together as a learning

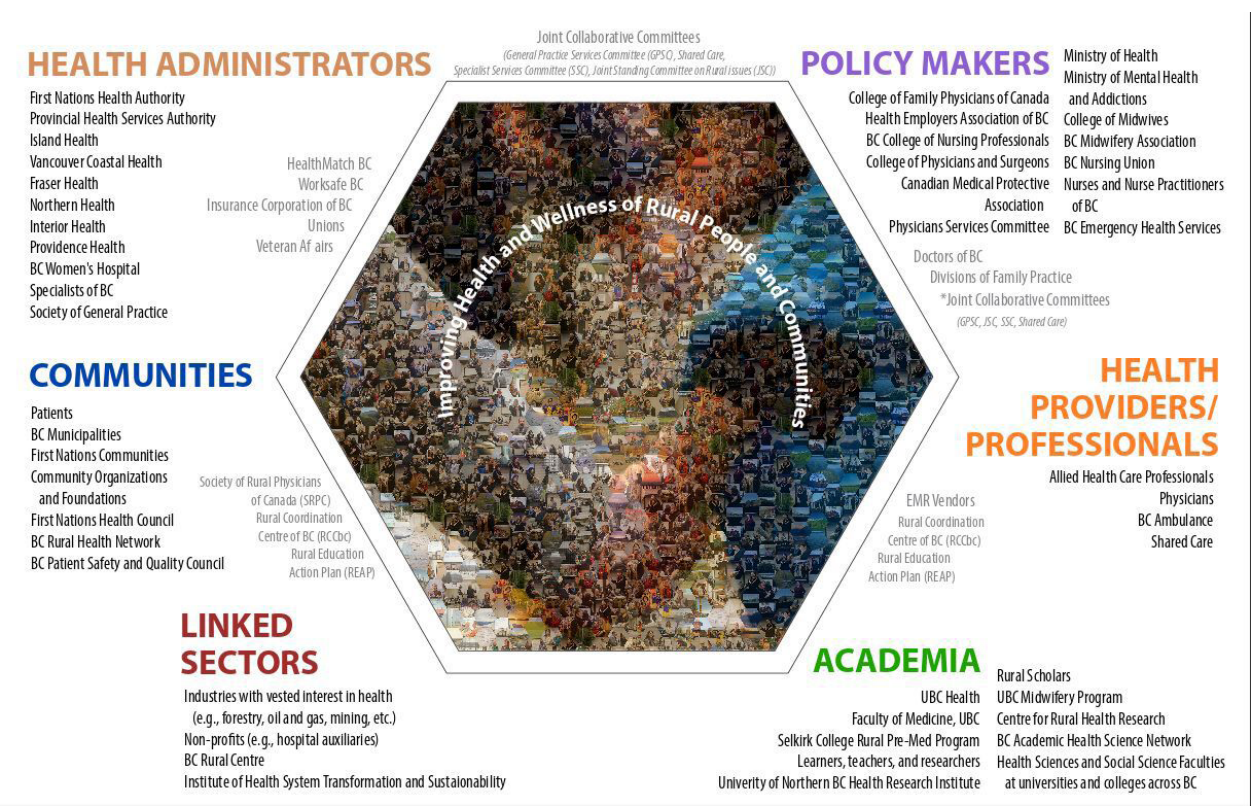

Figure 2 Partnership Pentagram Plus. 
In complex system undertakings, like health, whoever is not there provides a useful excuse for collective failure.

For example:

no policy-makers $=$ lack of will

no managers = too much bureaucracy and red tape

no health professionals = greedy doctors and unions

no academics = ivory tower rather than real world

no patients/communities = unrealistic expectations

no linked sectors = don't care about community

Figure 3 Scapegoats for collective failure.

community. This is foundational work with intrinsic value (eg, relationships).

This is woven with 'peer groups' of the six partners, collaborating with others from their perspective to explore their role in addressing the prioritised needs. They thus decide on, and commit to, actions they can contribute to the collective goal under their own governance framework. They then come back to the partnership groups to voice their commitment and modify where needed.

\section{Simultaneity}

When the partners work on identifying common interests and direction, they are all at the table together as opposed to a series of consultations (bipolar or tripolar meetings). In our experience, when all perspectives are in the room together and when others are seen as human beings, these handy scapegoats for collective failure (figure 3) fade away. All partners roll up their sleeves to work together on the goal they have collectively agreed on. The six partners cannot simply reach consensus that the sixth partner not in the room is the problem ('lack of political will', 'too much bureaucracy', 'ivory tower' and so on) This is particularly important in rural settings where often community engagement is hierarchical (we go to community to consult).

\section{IMPLEMENTATION}

Our practical enhancements of social accountability in action are:

1. Holding ourselves mutually accountable as social beings (relationships before action).

2. Serving the people, the healthcare system as a complement to governance or contractual accountability.

\section{Learning health eco-systems approach}

Recognising that there are a variety of interpretations of a learning health system, ${ }^{16}$ we moved the application of this model into socially accountable health system change ${ }^{11}$ by using the PPP as a framework for a learning health community in a learning health ecosystem. Recognising that we are in a complex adaptive health ecosystem, not an organisation, this learning community decides what to change and then what the impacts of the change mean together (the wisdom step in data to information to knowledge to wisdom ${ }^{17}$ ).

\section{Appreciative inquiry and deliberative dialogue}

Our processes underscored the importance of dialogue using an appreciative inquiry approach. This takes participants through a journey (Discover-Dream-DesignDeliver) looking at amplifying what is working and demonstrating practical outcomes. The exploration determines why this aspect is working and how we can expand its influence. In partnership with FNHA, we used a 'two-eyed seeing' approach that stresses the importance of viewing the world through both Western (what is considered to be mainstream) and Indigenous worldviews and ways of knowing. ${ }^{18-20}$ Deliberative dialogue principles aim to foster particular kinds of structured conversation that feature informed and reasoned discussion, attentive listening to understand the values underlying different views, weighing of reasons for and against a proposed action or policy (deliberation) and a desire to build towards common understanding and cocreation of action. ${ }^{21}$ These added to our appreciative inquiry approach. In a complex adaptive system, this type of feedback loop is an important vehicle for change. Some key considerations we have observed in our work include:

\section{Power}

In healthcare, we traditionally see power as making things happen through money and policy. There are many examples where changes have failed despite concentrations of both of these. The elements that we have implemented look initially at grounding what we want to change in community and serving the health and wellness of rural people and communities. Part of that is recognising that each partner brings power to cocreating and implementing any direction. That power manifests in a variety of ways, including people identifying what is important, needed policy changes, resource allocation and the clinicians'/community's view on what will work. An example of engagement at the community level is given (figure 4).

\section{The other side}

Using an appreciative inquiry approach helps develop where we want to go together and what each of us can do to get there. In any complex system, no matter how seemingly dysfunctional, something is working. A joint search, by a partnership table, for examples and analysing why it is working is far more productive than a SWOT analysis (strengths, weaknesses, opportunities, threats) of why something is not working. ${ }^{22}$ Instead of the other side becoming the enemy, they contribute to 'lifting the rock' with you, adjusting how you lift to accommodate their capacity.

\section{Breathing/weaving}

In applying this process, we have tried to stay away from creating new structures and instead support the functions of existing groups. Taking a developmental approach, we have facilitated the movement to simultaneously iterate 


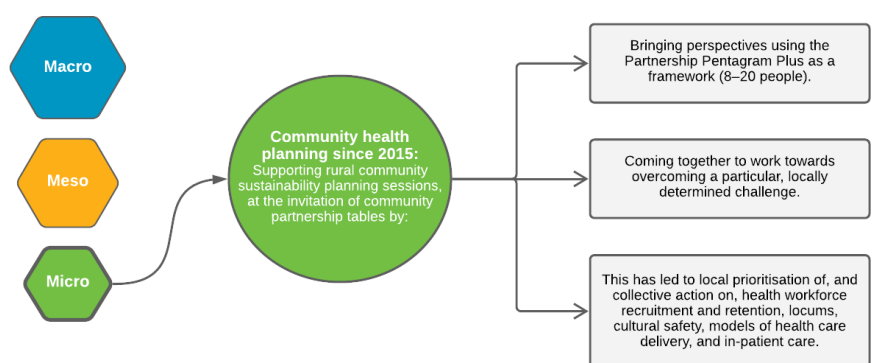

Figure 4 Application at a microlevel.

both the direction we are going and its implementation. This can be seen both in a vertical and horizontal 'weave' (figure 5).

\section{Horizontal weave}

We have differentiated between partner tables and peer tables and facilitated space for both.

Partner tables discover 'where we want to go together'. The Partnership Pentagram Plus partners meet, develop relationships and identify areas of priority to build common causes.

Peer Tables identify 'what I am going to do to help us get there'. The points of the partnership pentagram need safe space to explore what pieces of moving the common agenda forward they can pick up within their own organisations.

When hosting large gatherings, we allow space and time for both partner and peer tables to reflect with each other and iterate both the solution and practical application. It is crucial to recognise and contextualise power in this process.

\section{Vertical weave}

Embedding local (micro) perspectives at provincial tables as well as provincial leaders (macro) at community tables as they dialogue (figure 6).

\section{Scale}

All complex systems, including learning organisations, are composed of subsystems at various scales. Indeed, when the subsystems at any scale become "more than the

\section{Breathing \& Weaving}
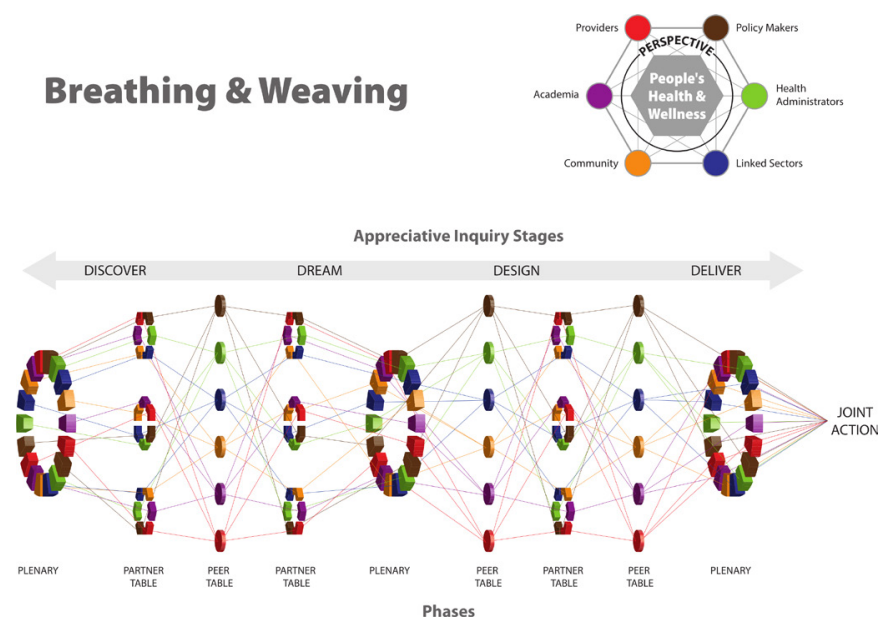

Figure 5 Breathing and weaving.

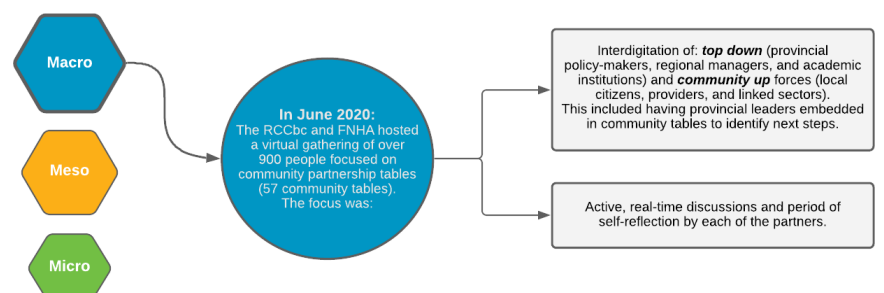

Figure 6 Application at a macrolevel. FNHA, First Nations Health Authority; RCCbc, Rural Coordination Centre of British Columbia.

sum of their parts', a higher order system emerges. This approach can be applied at micro (community level), meso (regional) and macro (provincial) levels. At each level, the functions are different but some aspects of relationships and feedback are consistent. In application, we look at a macrofunction outlining priorities and strategic direction. In healthcare, this needs to be shaped and driven by what works at a community (micro) level. ${ }^{23}$ At a mesolevel, function is around supporting those at the clinical interface in applying strategic directions (figure 7). It is also worth noting that the perspective one brings may depend on which level one is at (eg, a town Mayor might bring a policy perspective at a micro (community) table but a community perspective at a macro (provincial or national) table).

\section{ILLUSTRATION}

\section{Practical progress and lessons learned}

In January 2019, we facilitated a gathering with approximately 250 leaders from all six PPP perspectives. This was designed to create a feedback loop from rural and First Nations communities in BC with a focus on the implementation of Primary Care Networks in BC but the expectation that the lessons learnt would find greater application. We understand outcomes to be improvements (some listed below) in the healthcare ecosystem where we have applied this model. Given we are working in a complex system that defies the simple cause and effect that is typical in simple logic model designs, we have adopted a change-oriented conception of outcomes that is concerned with multichannel service transformations and partnership developments across multiple sectors concurrently. They are focused on observable service

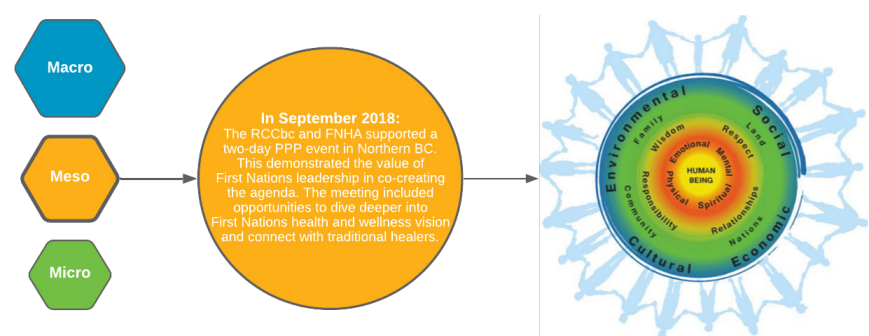

Figure 7 Application at a mesolevel. FNHA, First Nations Health Authority; RCCbc, Rural Coordination Centre of British Columbia. 
improvements and partnership creation that did not exist before our application of the model. Below is a short list of some key outcomes extending from our efforts.

\section{Practical outcomes}

- The collective development of key priority areas (virtually enhanced care, cultural safety and humility, teambased care (including emergency transport) and deeper community engagement) through facilitated sessions using appreciative inquiry and deliberative dialogue.

- Anchoring change in the broad system by attending to its impacts in the smallest and most isolated communities. This is in keeping with the sentiment often misascribed to Gandhi: 'The true measure of any society can be found in how it treats its most vulnerable members'. Primary consideration for innovations was that they should not widen but rather narrow the equity gap in health status. This resulted in agreement across all partners of the 'denominator communities' (the most isolated rural and First Nations communities). This has led to the impact in these communities being seen as a metric of system improvement, in addition to a traditional aggregated approach.

- Supporting 'collective perspective' tables for Community, Linked Sectors and Rural Providers. Some partners have significant infrastructure behind them, and others have no forum to work through to facilitate a 'collective perspective' on priorities and approaches. Resources are now dedicated to holding space for those partners who do not have the infrastructure to form a collective perspective on issued being discussed. This supports bringing of diverse perspectives brought by the different partners in the PPP on a more level playing field. An example of diversity of perspective would be when discussing transport, providers largely see this as emergency transport, while community sees it as travel to out-of-town appointments.

- The establishment of a virtual health and wellness collaborative (built as a learning community on the $\mathrm{PPP}$ ) for rural and First Nations BC. This is co-led by FNHA and Providence Health with support from RCCbc and Provincial Health Services Authority. This collaborative guided the implementation of Real Time Virtual Supports for rural and remote providers in BC with immediate video support from Intensivists, Pediatrics, Emergency Rooms (ER) and Maternity providers. This model mitigates geography and weather as an absolute barrier to the right team coming around the patient at the right time and place. Through live virtual connection based on previously established relationships, we reproduce some of the benefits of a large urban ER while supporting the local service teams. In many rural communities, the ER team consists of one physician, one nurse and two paramedics. Now, the team available to support patient care is greatly expanded through virtual connection. Any rural community can bring any one of four colleagues into the ER virtually within minutes to provide interdisciplinary support for as long as needed.

- Enhanced options for access to care for First Nations people in remote and isolated communities and those living away from their home communities (eg, in the city) through the First Nations Virtual Doctor of the Day and supporting services, as well as the specialty service, First Nations Virtual Substance Use and Psychiatry Services. This is linked to 15 First Nations led primary care initiatives. These initiatives provide individuals access to culturally safe care linked to their community, family strengths and social ties. In part, this is intended to mitigate the isolation that is a part of urban migration. This has been accentuated during the COVID-19 pandemic where a number of First Nations communities 'locked down' to protect themselves. They had been receiving visiting clinicians, but this was no longer an option and a virtual culturally safe service provided an alternative. Both of these initiatives have accentuated the digital divide and have highlighted this an area to actively work on.

\section{Lessons learned}

Time intensive

A significant amount of time was spent in dialogue incrementally introducing and engaging people in this process. Smaller gatherings and touch points were held over at least 2 years, resulting in enough critical mass to start seeing the changes we now witness regularly. This takes time, however, once the space has been created it does allow for pivoting in short time frames.

\section{Attribution}

In a complex adaptive system, it is difficult to attribute success to any one process. We have measured success in an iterative process. This includes signals such as multiple peer groups seeing the process contributing to an change and the timing of those changes. Ongoing data gathering, sharing and analysis will help ensure we are moving in the right direction.

\section{Growing depth of facilitation}

Facilitators explain and guide the different functions of peer groups and partner groups in our gatherings. Training and supporting a cohort of facilitators and materials is essential in scaling this work across the system. The Facilitators support the continual reinforcement of principles like perspective and simultaneity essential to supporting an appreciative approach that shifts things that need to shift.

\section{Navigating silos}

Navigating silos is complex and requires direct attention both within and between peer groups. Our approach has been to actively identify these in a non-judgemental way and then intentionally working on making them more porous primarily through relationship building. 


\section{Practical application}

Continual attention needs to be given to translating the collective goodwill achieved through this appreciative inquiry process into practical changes that directly address health inequities. This requires organisation(s) to invest in keeping momentum with the social accountability theme at the core of relationships. An example of this would be the establishment of positive memoranda of collaboration among partners that help keep the focus on both innovation and stabilisation once new services are launched and operating.

\section{First Nations}

Political and health leadership is core to any success we achieve together, in and for BC.

\section{CONCLUSION}

We have succeeded in moving beyond the rhetoric of social accountability to its practical application in a complex system of healthcare. The PPP framework, when applied with appreciative inquiry and deliberative dialogue approaches, has produced meaningful socially accountable change in rural communities, and First Nations communities in BC, Canada. This model is a potential vehicle to be adapted to other contexts by taking a learning or developmental approach in determining how it can be applied at different scales.

- The work of meaningful system change is founded on the valuing and building of relationships with safe space and trust. By holding space to listen and understand other perspectives, we better grasp what our most effective next step is.

- The PPP is an effective framework to consider which perspectives to bring forward to be applied at a variety of levels (local, regional or system wide).

- The process (simultaneity, breathing and weaving, appreciative inquiry, deliberative dialogue) leads to a situation in which partner groups prioritise and align action, and peer groups can decide and commit to what action they will take.

The foundational relationships built through the PPP act as the catalyst for ongoing socially accountable change in the health and wellness care systems in BC including rural First Nations communities. We welcome the opportunity to work and learn with others on potential application in their systems.

\section{Author affiliations}

${ }^{1}$ Family Practice, The University of British Columbia Faculty of Medicine, Vancouver, British Columbia, Canada

${ }^{2}$ Rural Coordination Centre of British Columbia, Vancouver, British Columbia, Canada ${ }^{3}$ First Nations Health Authority, West Vancouver, British Columbia, Canada ${ }^{4}$ School of Nursing, University of British Columbia Okanagan, Kelowna, British Columbia, Canada

${ }^{5}$ University of British Columbia Northern Medical Program, The University of Northern British Columbia, Prince George, British Columbia, Canada ${ }^{6}$ Northern Ontario School of Medicine, Thunder Bay, Ontario, Canada ${ }^{7}$ Health Research Institute, University of Northern British Columbia, Prince George, British Columbia, Canada

\section{Twitter David Snadden @dsnadden}

Contributors RM: wrote the majority of the first draft of the manuscript and provided input on the development of the figures. $\mathrm{MH}$ : provided input to the overall manuscript and its presentation including writing of text and development of the figures. RW: provided input to the overall manuscript and its presentation including writing of text and development of the figures. NO: provided input to the overall manuscript and its presentation including writing of text and development of the figures. DS: provided input to the overall manuscript and its presentation including writing of text and development of the figures. RS: provided input to the overall manuscript and its presentation including writing of text and development of the figures. GB: provided input to the overall manuscript and its presentation including writing of text and development of the figures. SG: provided input to overall manuscript and its presentation including writing of text and development of the figures. All authors approved the final version of the manuscript.

Funding The authors have not declared a specific grant for this research from any funding agency in the public, commercial or not-for-profit sectors.

Competing interests None declared.

Patient consent for publication Not required.

Provenance and peer review Not commissioned; externally peer reviewed.

Open access This is an open access article distributed in accordance with the Creative Commons Attribution Non Commercial (CC BY-NC 4.0) license, which permits others to distribute, remix, adapt, build upon this work non-commercially, and license their derivative works on different terms, provided the original work is properly cited, appropriate credit is given, any changes made indicated, and the use is non-commercial. See: http://creativecommons.org/licenses/by-nc/4.0/.

\section{ORCID iDs}

Ray Markham http://orcid.org/0000-0002-3326-6871

David Snadden http://orcid.org/0000-0002-4818-1184

Georgia Betkus http://orcid.org/0000-0001-5539-5546

\section{REFERENCES}

1 Public Health Agency of Canada. Key health inequities in Canada: a national portrait, 2018. Available: https://www.canada.ca/content/ dam/phac-aspc/documents/services/publications/science-research/ key-health-inequalities-canada-national-portrait-executive-summary/ key_health_inequalities_full_report-eng.pdf

2 International Labour Organization. Global evidence on inequities in rural health protection: new data on health deficits in health coverage for 174 countries. Geneva, 2015. Available: https://reliefweb.int/sites/ reliefweb.int/files/resources/RessourcePDF.pdf

3 Hanlon N, Halseth G. The greying of resource communities in northern British Columbia: implications for health care delivery in already-underserviced communities. The Canadian Geographer/Le G?ographe canadien 2005;49:1-24.

4 Fors M. Geographical narcissism in psychotherapy: Countermapping urban assumptions about power, space, and time. Psychoanalytic Psychology 2018;35:446-53.

5 Turpel-Lafond ME. In plain sight: addressing Indigenous-specific racism and discrimination in bc health care. Victoria: Government of British Columbia, 2020.

6 Mitchell T, Arseneau C. Colonial trauma: complex, continuous, collective, cumulative and compounding effects on the health of Indigenous peoples in Canada and beyond. Int $J$ Indig Health 2019;14:74-94

7 Truth and Reconciliation Commission of C. The survivors speak: a report of the truth and reconciliation Commission of Canada, 2015. Available: https://central.bac-lac.gc.ca/.item?id=IR4-5-2015-eng\& $\mathrm{op}=\mathrm{pdf \& app=Library}$

8 Government of British Columbia. Declaration on the Rights of Indigenous Peoples Act [SBC 2019] Chapter 44, Article 23. Available: https://www.bclaws.gov.bc.ca/civix/document/id/complete/statreg/ 19044

9 World Health Organization. Towards unity for health: challenges and opportunities for partnership in health development: a working paper / Charles Boelen. Geneva, Switzerland: World Health Organization, 2000.

10 Woollard RF. Caring for a common future: medical schools' social accountability. Med Educ 2006;40:301-13.

11 Agarwal S, Heltberg R, Diachok M. Scaling-up social accountability in world bank operations. Washington, DC: World Bank, 2009. 
12 Boelen C, Heck JE, World Health Organization. Division of development of human resources for $\mathrm{H}$. defining and measuring the social accountability of medical schools / Charles Boelen and Jeffery E. Heck. Geneva: World Health Organization, 1995.

13 Bushe GR. Appreciative inquiry: Theory and critique. In: Boje D, Burnes B, Hassard J, eds. The Routledge companion to organizational change. Oxford, UK: Routledge, 2012: 87-103.

14 Magruder-Watkins J, Stavros J. Appreciative Inquiry: OD in the Post-Modern age. In: Rothwell W, Stavros J, Sullivan R, et al, eds. Practicing organization development: a guide for leading change. 3rd Edition. Jossey-Bass, 2009.

15 Friedman C, Rigby M. Conceptualising and creating a global learning health system. Int J Med Inform 2013;82:e63-71.

16 Menear M, Blanchette M-A, Demers-Payette O, et al. A framework for value-creating learning health systems. Health Res Policy Syst 2019;17:79.

17 Rowley J. The wisdom hierarchy: representations of the DIKW hierarchy. J Inf Sci 2007;33:163-80.
18 Wright AL, Gabel C, Ballantyne M, et al. Using Two-Eyed seeing in research with Indigenous people: an integrative review. Int J Qual Methods 2019;18:160940691986969.

19 Wilson N, Harris L, Joseph-Rear A, et al. Water is Medicine: Reimagining Water Security through Tr'ondëk Hwëch'in Relationships to Treated and Traditional Water Sources in Yukon, Canada. Water 2019;11:624.

20 Allen L, Hatala A, ljaz S, et al. Indigenous-Led health care partnerships in Canada. CMAJ 2020;192:E208-16.

21 Acosta AM, Oelke ND, Lima MA. Theoretical considerations of deliberative dialogue: contributions for nursing practice, policy and research. Texto Contexto Enferm 2017;26:e0520017.

22 Woollard RF. Building health systems based on People's needs. Poster at AMEE Conference. Helsinki, 2017.

23 Strasser R, Strasser S. Reimagining primary health care workforce in rural and underserved settings (English). health, nutrition, and population (HNP) discussion paper. Washington, DC: World Bank Group, 2020. http://documents.worldbank.org/curated/en/ 304851606975759118/Reimagining-Primary-Health-Care-Workforcein-Rural-and-Underserved-Settings 